\title{
Factors Influencing Homosexuality in Men: A Term Paper
}

\author{
Margie P. Vito, Msc.
}

ERM Department, Bohol Island State University Clarin Campus, Poblacion Norte Clarin, Bohol, Philippines

Received: 27 Sept 2020; Received in revised form: 18 Nov 2020; Accepted: 21 Nov 2020; Available online: 28 Nov 2020

(C)2020 The Author(s). Published by Infogain Publication. This is an open access article under the CC BY license

(https://creativecommons.org/licenses/by/4.0/).

\begin{abstract}
There are several factors that influenced homosexuality. In this paper, significant areas in human development were reviewed how each of these aspects played a role in homosexual individuals. These paper elaborated the factors that may have a bearing on homosexuality namely: hereditary factors, linkage of Xq28 gene, environmental, epigenetic influence, religion and culture. It was found out these factors displayed different ranges in triggering out homosexuality. This review paper is essential in understanding the root of how homosexuals are developed. This paper will give clarity that homosexuality is a natural phenomenon and not a human deviation of nature. Hence, homosexuality needs to be accepted universally.
\end{abstract}

Keywords-Epigenetics, Ethics, Gay, Heterosexuality, and Hereditary.

\section{INTRODUCTION}

Sexual orientation refers to an enduring pattern of emotional, romantic and/or sexual attractions to men, women or both sexes. It is a sexually differentiated trait over $90 \%$ of men who are attracted to women and vice versa. This is affected by mechanisms that result to differentiated characteristics that could be behavioral, physiological, or morphological traits that are significantly different in heterosexual and homosexual populations (Balthazar, 2011). Some are even influenced by environmental factors (Addis et al., 2010). In males and females, sexual feelings and behavior are displayed in different ranges. It is even used as a barometer for his or her moral or religious beliefs described in various cultures and nations throughout the world. Many cultures used identity labels to describe people who expressed these attractions. The most frequent titles are lesbians (women attracted to women), gay men (men attracted to men), and bisexual people (men or women attracted to both sexes). To many people, most men are attracted to women, and vice versa, seem to be the natural order of things or the appropriate manifestation of biological instinct, reinforced by education, religion, and the law (LeVay et al., 1994). Generally, discussion regarding sexuality, particularly in same-sex attraction, has a wider scope which is ranging from the philosophical discussion to scientific and psychological concepts. It 4 is determined by education and social constraints. In the community, there were three categories of sexual orientation; heterosexual, bisexual and homosexual. However, this paper gives more emphasis only on homosexuality, specifically in men. Homosexuality derived from two Latin words "homo" which means same and "sexus" meaning sex. The term homosexuality was coined by a German psychologist named Karoly Maria Benkert in the late 19th century (Brent, 2015). Homosexual behavior has existed throughout human history and in most, perhaps all human cultures (Chauncey, 1985). Cross-cultural and historical qualify the breadth of homosexual experience while medical studies primarily from the Contemporary West, quantify its depth.

The Melanesian example of homosexual behavior is wellknown, with $10-20 \%$ of Melanesian societies requiring all men to participate in homosexual as well as heterosexual sex (Herdt, 1984). In Southern China, at the turn of the last century, 100,000 women joined a marriage resistance movement that included many lifelong homosexual partnerships (Sankar, 1986). In Pacific island societies other than in Melanesia, such as Tahiti and Hawaii, homosexual behavior was expected prior to Western influence (Morris, 1990). In native North America, at least 137 societies had institutional roles for transgender commonly associated with homosexual behavior. At present, there had been a lot of stirring controversies 
among homosexual individuals. One study that provokes controversy is the research on sexual orientation, simply referred to as gay gene research (Lautmann et al., 1993). Research on the origin of sexual orientation had received public attention specifically on the findings with the notion of relatively simple links between genes and sexual orientation. There are a lot of questions on how homosexuality occurs or what influenced homosexuality as a whole. The answer to these questions is the aim of this review paper. Specifically, this paper will verify facts from series of studies and literature on homosexuality occurrence if it is a viral illness that can be genetically treated, triggered by individual's choice of lifestyle, influenced by environmental factors or inherited genetically from parents. Through this study, awareness and full understanding on homosexuals will be attained for gender equality and for their full acceptance in society.

\section{OBJECTIVES OF THE STUDY}

This study generally aims to determine the causes of homosexuality. Specifically, to identify which of the following factors greatly influenced homosexuality in men, namely; 1. Genetic Factors 2. Linkage of Xq28 gene 3. Environmental Factors 4. Epigenetic Influence 5. Religion and Culture

\section{SIGNIFICANCE OF THE STUDY}

In today's society, many people wonder how come there is a rapid growth of homosexuals. Hence, this paper provides sufficient information to help people understand the various aspects of homosexuality. The study also further give clarification on the misconceptions and controversies involved in homosexuality. This broaden the society's knowledge and help them accept homosexuals. With the evidence that were provided in this paper, these will give different 5 perspective and views for everyone to be able to evaluate the positive and negative aspects of homosexuality. This also help parents in dealing with their children who have sexuality problems and for them to find out the cause of why he/she is acting that way

\section{EVIDENCE OF FACTORS INFLUENCING HOMOSEXUALITY}

\subsection{Genetic Factor}

Hereditary factors that contribute to sexual orientation in men are evident from a number of families and twin studies (Dawood, 2009). Family studies have shown homosexuality to be more common in biological relatives of heterosexual men or compared to general population surveys; thus, it is familial or cluster in families (Pillard and Weinrich, 1986). These studies find that brothers of homosexual probands (index subject in the family) are homosexual $7 \%$ to $22 \%$ of the time, with most findings around $10 \%$. Those studies that corroborated the family history information from the homosexual proband directly with the proband's relatives have found high rates of agreement (Hershberger, 1997). However, when Kirk (1999) applied the family history method with the general population (mostly heterosexual) probands using the cotwin as a corroborator in a twin study, lower accuracy was found. These findings are consistent with homosexual probands more accurately reporting sexual orientation information for their family members compared to heterosexual probands and are among the reasons some previous family studies have used general population survey rates as a comparison group. A previous finding of excess maternal transmission (relative to paternal) Hamer et al., (1993) led to an initial focus on X chromosome in linkage studies since a gene variant on $\mathrm{X}$ chromosome influencing male sexual orientation would be one potential explanation of excess maternal transmission. The main finding from these family studies has been male sexual orientation is significantly familial, though twin studies are required to assess if any of the familiality derives from hereditary contributions. On the other hand, twin studies consistently find higher concordances for sexual orientation for identical twins compared to same-sex fraternal twins, though the exact concordance varies by study. Some studies report individually on male twins, while others combine information on male and female twins. Yet, overall genetic contributions have been estimated to account for up to about half of the variation in the trait of male sexual orientation based on larger studies using more recent methods (Langstrom et al., 2010).

\subsection{Linkage of Xq28 gene}

Several lines of evidence have implicated genetic factors in homosexuality. The most compelling observation has been the report of the genetic linkage of male homosexuality to microsatellite markers on the $\mathrm{X}$ chromosome. The Xq28 locus has the component with heritable maternal material that influences homosexual predisposition. As such, related males (brothers, maternal uncles, and cousins) should share an excessive amount of allelic material in that region (Rice et al., 1999). Although the terminal portion of Xq28 may code for homosexuality as indicated by markers, it is difficult to establish any direct gene products. Linkage studied aim to map genomic regions that are linked to the studied trait in the families. This is the strongest support for the genetic component in 
male sexual orientation. This 6 showed the involvement of an X-linked gene at position $\mathrm{Xq} 28$ based on family recurrence patterns and molecular analysis of $\mathrm{X}$ chromosome in sibships in which there were multiple brothers with a homosexual orientation (Hamer et al., 1993). Specifically, Hamer and colleagues obtained family history information from 76 gay male index and 40 gay brother pairs about the sexual orientation of the first, second and third-degree relatives with follow-up interviews of smaller proportion relatives. From their study, they have reported increased rates of homosexual orientation in maternal uncles and male cousins through maternal aunts, which was suggestive of X-linked inheritance. Moreover, molecular analysis of $\mathrm{X}$ chromosome revealed that excess of allele sharing in the region of Xq28 in 40 homosexual brother pairs (6) and to a lesser extent in a follow-up study of 33 additional pairs (7). However, the aforementioned results were being questioned empirically and theoretically (Barron, 1993). Most agree that homosexual orientation is not a basic Mendelian trait. There would be strong evidence for Xlinkage; this finding was not replicated by other groups studying 54 such pairs from U.S. (Rice, Risch and Ebers, 1999). Since the results of the original Xq28 have never been replicated to such a significant degree, the validity of the outcome was weakened. It is quite evident from this that as the sample size becomes larger, the more selective the visibility is, and such relationship diminished. Another explanation for the findings is that $\mathrm{Xq} 28$ continues to only be a plausible factor of male homosexuality as females and heterosexual males show no excessive links. These findings also lack of paternal transmission for Xq28 in women (Heu et al., 1995).

\subsubsection{Autosomal Chromosome Linkage}

An autosome is a chromosome that is not an allosome (sex chromosome) (Griffifths, 1999). It appears in pairs whose members have the same form but differs from other pairs in a diploid cell, whereas members of an allosome pair may differ from one another and determine by sex. Autosomal chromosome can be inherited from either parent. In line with homosexuality, another factor that affects it can be explained by the trait expressed, specifically maternal characteristics. A study of LeVan (1994) posited that most gay males relatives of gay men on the mother's side of the family. This possibility may be due to the subject somehow that knew more about their maternal relatives with gay relatives distributed evenly on both parents side. Another is while being transmitted by both parents, it is expressed only in one sex-m (males). When expressed, the trait reduces the reproductive rate and must be disproportionately passed on by their mother. The third possibility is $\mathrm{X}$ chromosome linkage. Man has two sex chromosomes; $\mathrm{Y}$ chromosome inherited from his father and $\mathrm{X}$ which is cut and pasted from the two $\mathrm{X}$ chromosomes carried by the mother. Thus, any trait that is influenced by the gene on $\mathrm{X}$ chromosome will be inherited to the mother's side and preferentially be observed in brothers, maternal uncles, and cousins, which is exactly the observed pattern (LeVan,1994).

\subsection{Role of Environmental Factors}

\subsubsection{High Estrogen levels}

An estrogen is a group of female sex hormones directed to develop female sexual characteristics. Steroidal estrogen is cholesterol derivatives comprising a group of structurally related hormonally active molecules that control sex and growth hormones. Estrone is an 7 estrogenic hormone secreted by the ovary as well as adipose tissue. Estradiol is the predominant hormone present in females and males. In an essays of UK (November 2013) estrogen-containing food is said to be a homosexual risk. Foods containing high level of estrogen include chicken, soybeans, and dairy products like milk may put males at risk for change in sexuality by altering the hormonal level of estrogen thus changing secondary characteristics in males such as enlargement of breast (gynecomastia), change in psychological behaviours, erectile dysfunction and decrease in libido. There are different types of non-steroidal estrogens; Xenoestrogen, Phytoestrogen, and Mycoestrogen. Xenoestrogens are type of xenohormone that imitates estrogen. This includes commercially non-organic meat such as beef, chicken and pork, dairy products including milk, cheese and ice cream. Phytoestrogens are coming from plant products such as soy products, cereals, breads, legumes, meat products and other processed foods that contain soy, vegetables, fruit, alcoholic and non-alcoholic beverages. Finally, mycoestrogen are produced by fungi which are common in stored grain and silage UK (November 2013).

\subsubsection{Phthalate Exposure}

Phthalates are found in vinyl products, including vinyl flooring, PVC shower curtains, plastic furniture, and even the plastic coating of the insides of dishwashing machines. It was also found in commonly used personal care products such as baby shampoos, baby lotions, and baby powders. This chemical found in the mentioned products tends to feminized boys altering their brains to express more feminine characteristics, as found by a scientist at the University of Rochester. The feminization process happens during pregnancy when phthalate exposure causes hormone disruptions in the unborn baby. This chemical 
feminizes male by disrupting the action of the hormone testosterone (Hernandez-Diaz et al., 2009).

\subsubsection{Biochemical Imbalance Involving Copper and Zinc}

Copper and zinc relate closely to our secondary sex characteristic, which means our attitude and feelings about sexuality and, among others. Many, if not all homosexuals, have too much copper and not zinc. Many children are being born homosexual because of zinc deficiency and copper excess in mothers. This is not a genetic error, which means this is not in genes or chromosomes, but congenital abnormality. Congenital imbalances are mainly due to nutritional problems in one's mother or perhaps toxins in the mother's body that affect the growing fetus (Wilson, 2014).

\subsection{Epigenetic Influence}

Epigenetics is the control of gene expression by factors other than the genes. These factors may be pre-natal or post natal (occurring at any lifetime of age), often coming from the exterior environment, both biological and social. Epigenetic marks or changes in protein configurations around DNA can be passed on to descendants but not to some extent (Whitehead, 2012). Epigenetic factors may certainly be one factor in the mix of homosexuality. In the study of Rice et al., (2012), described the epigenetic factor causing homosexuality. They integrated the theory from evolutionary genetics with recent developments in gene expression regulation and 50 years of research on androgen-dependent sexual development. The first find that the existing mammalian sexual development is incomplete, with missing a system of the component to canalize androgen signaling during fetal development. The response to circulating testosterone is boosted in $8 \mathrm{XY}$ fetuses and blunted in XX fetuses. They integrate these data with current findings from epigenetic control of gene expression, especially in embryonic stem cells to develop and support a mathematical model of epigenetic-based canalization of sexual development empirically. The model predicts the evolution of homosexuality in both sexes when canalizing epi-marks carry over across generations with nonzero probability. It is now well established that a parents epi-marks sometimes carryover across generations and influence the phenotype offspring (Morgan and Whitelaw, 2008). However, as pointed out by Whitehead (2012), an explanation of homosexuality is a theory only. Although there have been a lot of attempts within at least 13 different research fields to show a strong biological basis for homosexuality, all have failed. This presents a genetic model for the inheritance of epigenetic marks, which showed that prenatal influence could be possible and can even be as high as $50 \%$. It is still essential to do practical work to test this theory.

4.5 Legal, Genetics and Christian Views on
Homosexuality

Homosexuality has been debated throughout history, and many theories had risen to discuss it. The Natural Law theory in its essence is about being against unnatural attractions. As stated by Plato (a natural law supporter) that opposite-sex sex acts cause pleasure by nature, while same-sex sexuality is unnatural (Pickett, 2015). In contrast, a new Queer theory was developed to support gay and lesbian individuals, and its core; it supports the equality of all people, not just homosexuals (Stychin, 2005). While homosexual activists have staked their political strategy on claims that homosexuality is an inherited trait, like lefthandedness, for a significant minority of human beings (Mohler, 2009). Homosexuality is a widespread phenomenon that has been around for centuries. Homosexual discrimination has always been a critical issue affecting many lives all over the world. In some cultures, they accept and embrace homosexuality, while others are strictly against it. Laws differ from country to country and from region to region all around the world. In fact, homosexual acts between consenting adults are known to be illegal in about 70 out of the 195 countries of the world. Homosexual sex acts may be illegal, especially under sodomy laws, and where they are legal, the age of consent often differs from country to country. In some cases, homosexuals are prosecuted under vaguely worded "public decency" or morality laws. Some countries have special laws preventing certain public expressions of homosexuality (Mijnssen, 2013). In every country, homosexuality is tackled by its rules, which prohibit, accept, or even support homosexuals. The first country to recognize same-sex marriage was the Netherlands in 2001. Since then same-sex marriages were subsequently identified in Belgium (2003), Spain (2005), Canada (2005), South Africa (2006), Norway and Sweden (2009), Portugal ,Argentina and Ice-land (2010), Denmark (2012), Brazil (2013) , France (2013), Uruguiay(2013) ,New Zealand (2013), Luxembourg (2015) and all jurisdictions in the United States (2015). In Slovenia and in Finland, same-sex marriage is to become effective in 2015 and 2017, respectively. It is also recognized in two Mexican states, namely Quintana Roo and Coahuila, and the Mexican federal district of Mexico City. England, Wales and Scotland, constituent countries of the United Kingdom, have also legalized same-sex marriage but it remains illegal in Northern 9 Ireland. Other legal recognition of same sex relationships (offering fewer benefits than marriage) include civil unions and domestic 
partnerships. On the other end of the spectrum, several countries impose the death penalty for homosexual acts, per the application of some interpretations of Shari'a law. As of 2015, these include the following countries namely; Afghanistan, Brunei, Mauritania, Sudan, Iran, Qatar, Saudi Arabia, United Arab Emirates, Yemen and northern Nigeria (Jones, 2015). In Saudi Arabia, the maximum punishment for homosexuality is public execution. However, the government will use other punishments e.g., fines, jail time, and whipping as alternatives, unless it feels that homosexuals are challenging state authority by engaging in LGBT social movements (Dahir, 2002). Iran had the largest number of its citizens to execute for homosexuality. Since the 1979 Islamic revolution in Iran, the Iranian government has performed more than 4,000 people charged with homosexual acts (Vexen, 2014). The United Nations Human Rights Committee has also ruled that such laws violate the right to privacy guaranteed in the Universal Declaration of Human Rights and the International Covenant on Civil and Political Rights since 1994. Yet, many, even those with secular constitutions, continue to outlaw homosexuality, though only in the minority (Iran, Saudi Arabia ,Yemen and and Afghanistan is still punishable by death except for Lebanon, which has an internal effort to legalize it (Qadiry,2013).However, Muslim countries where homosexuality is not criminalized include Indonesia, the world's largest Muslim nation by population Turkey, Iraq ,Jordan ,Bahrain, Kazakhstan, Kyrgyztan, Tajikistan, Kosovo and Albania.

Conservative Christians believe that homosexual behavior is sinful, not because of scientific evidence or the absence of a biological basis, but because the Bible is so evident in its condemnation of all homosexual acts, and even of homosexual desire (Romans 1: 27). The Rice and Ebers study does reveal the weakness of the biological argument put forward by homosexual activists, but evangelicals must be cautious in denying the possibility of any physical factors related to homosexuality. Both severe and ludicrous ideas are now put forth claiming a genetic basis for, among other things, alcoholism, gambling addictions, violent behavior, and even excessive television watching. All of these represent efforts to remove social stigma and to classify sinful actions as usual, or at least understandable. The flight from moral responsibility is a hallmark of the modern age. We hope for modern science to heal our diseases and excuse our sins. The Bible will not allow this evasion. Our sinful behavior, rooted in biology or not, is a matter for which we are fully accountable. After all, as the 10 Psalmist confessed: "Behold, I was brought forth in iniquity, and in sin my mother conceived me" (Psalm 51:5). The total depravity doctrine reminds us that no part of ourselves is free from sin and its injury. That certainly includes our genetic code as well. As the church father Ambrose of Milan (340-397) stated, "Before we are born we are infected with the contagion, and before we see the light of day we experience the injury of our origin." In the end, the scientific evidence is not morally necessary, though it may be medically useful. The church's witness to the biblical condemnation of homosexuality as sin is a crucial test of faithfulness, no matter where the biological research may lead. The church must take its stand on the Word of God, and leave the genes to the geneticists (Mohler, 2009).

Overall, genetics accounted for around 35 per cent of the differences between men in homosexual behavior and other individual-specific environmental factors (that is, not societal attitudes, family or parenting which are shared by twins) accounted for around 64 per cent. In other words, men become gay or straight because of different developmental pathways, not just one pathway (Rahman, 2008).

\section{CONCLUSION}

Homosexuality is observed in the animal kingdom in a large number of species, therefore it can be concluded that it is a natural phenomenon and not a human deviation of nature. Although, in dealing with homosexuality it is done differently in different aspects, regarding the law, nature, culture, and religion. However, homosexuality should be accepted universally, and discrimination against it should not be tolerated. This is because of the fact that homosexual behavior is primarily shaped by genetics and random environmental factors (Rahman, 2008). Thus, as the current evidence suggests, regardless of future studies, it is likely a multitude of possible genes working in conjunction with environmental factors and triggers that produces homosexual behavior.

\section{REFERENCES}

[1] Addis ME, Mansfield AK, Syzdek MR. Is "Masculinity" a Problem?: Framing the Effects of Gendered Social Learning in Men. Psychology of Men \& Masculinity. 2010;11:77-90.

[2] Baltazar, J.2011. Minireview: Hormones and Human Sexual Orientation. Endocrinology. Vol.152:2937-2947

[3] M. Baron, Br. Med. 1. 307, 337 (1993).

[4] Chauncey, G. 1989. From Sexual Inversion to Homosexuality: The Changing Medical Conceptualization of Female'Deviance,'. Passion and power: Sexuality in history, 109, 1890-1940.

[5] Dawood, K., Bailey, J. M., \& Martin, N. G. 2009. Genetic and environmental influences on sexual orientation. In 
Handbook of behavior genetics (pp. 269-279). Springer New York.

[6] Dahir, M .2002. "Is Beheading Really the Punishment for Homosexuality in Saudi Arabia?". Archived from the original on .

[7] Essays, UK. (November 2013). Estrogen Containing Foods A Homosexual Risk.

[8] Griffiths, Anthony J. F. 1999. An Introduction to genetic analysis. New York: W.H. Freeman. ISBN 0-7167-3771-X.

[9] Hamer, D. H., Hu, S., Magnuson, V. L., Hu, N., \& Pattatucci, A. M. (1993). A linkage between DNA markers on the $\mathrm{X}$ chromosome and male sexual orientation. Science, 261(5119), 321-327.

[10] Herdt, G. H. 1984. Semen transactions in Sambia culture. Ritualized homosexuality in 11 Melanesia, 167-210.

[11] Hernández-Díaz S, Mitchell AA, Kelley KE, Calafat AM, Hauser R . 2009. "Medications as a potential source of exposure to phthalates in the U.S. population". Environ. Health Perspect. 117 (2): 185-9.

[12] Hershberger, S. L., Pilkington, N. W., \& D'Augelli, A. R. 1997. Predictors of suicide attempts among gay, lesbian, and bisexual youth. Journal of Adolescent Research, 12(4), 477497.

[13] $\mathrm{Hu}, \mathrm{S}$., et al. Linkage between sexual orientation and chromosome Xq28 in males but not in females. Nature Genetics. 1995; 11:248-256

[14] Jones, S.2015. "76 Countries Where Anti-Gay Laws Are As Bad As Or Worse Than Russia's

[15] Rüdiger Lautmann, ed., Homosexualität -.Handbuch der Theorie- und Forschungsgeschichte (Campus Verlag: Frankfurt am Main, 1993); Vern Bullough, Science in the Bedroom: The History of Sex Research (Basic Books: NewYork, 1994).

[16] Kirk, K. M., Bailey, J. M., \& Martin, N. G. 1999. How accurate is the family history method for assessing siblings' sexual orientation?. Archives of sexual behavior, 28(2), 129137.

[17] Långström, N., Rahman, Q., Carlström, E., \& Lichtenstein, P. 2010. Genetic and environmental effects on same-sex sexual behavior: A population study of twins in Sweden. Archives of sexual behavior, 39(1), 75-80.

[18] LeVay, S., Hamer, D. 1994. Evidence of Biological Influence in Male Homosexuality.Scientific American Journal. Vol.253:44-49

[19] Mijnssen, I .2013. "Why Russia Fears the Gay". Truthdig.

[20] Morgan, D. K., \& Whitelaw, E. 2008. The case for transgenerational epigenetic inheritance in humans. Mammalian Genome, 19(6), 394-397.

[21] Mohler,A.2009.Then Again,Maybe Not:The Gay Gene Theory Takes a Hit.

[22] Morris, R. J. 1990. Aikāne: Accounts of Hawaiian SameSex Relationships in the Journals of Captain Cook's Third Voyage (1776-80). Journal of homosexuality, 19(4), 21-54.

[23] Rahman,Q.2008.Homosexual behavior due to genetic and environmental factors. Psychology and Sociology 17:21
[24] Rice, G., Anderson, C., Risch, N., \& Ebers, G. 1999. Male homosexuality: Absence of linkage to microsatellite markers at Xq28. Science, 284(5414), 665-667.

[25] Rice, W. R., Friberg, U., \& Gavrilets, S. 2012. Homosexuality as a consequence of epigenetically canalized sexual development. The Quarterly review of biology, 87(4), 343-368.

[26] Sankar, A. 1986. Sisters and brothers, lovers and enemies: Marriage resistance in Southern Kwangtung. Journal of homosexuality, 11(3-4), 69-82.

[27] Pickett, Brent, "Homosexuality", The Stanford Encyclopedia of Philosophy .2015. Edward N. Zalta

[28] Pillard, R. C., \& Weinrich, J. D. 1986. Evidence of familial nature of male homosexuality. Archives of General Psychiatry, 43(8), 808.

[29] Vexen ,C .2014. "The Battle Between Monotheism and Homosexuality: Religious Prejudice Versus Equality: Islam".

[30] Whitehead, N.2011. Neither genes nor choice: Same-sex attraction is mostly a unique reaction to 12 environmental factors. Journal of Human Sexuality, 3, 81-114.

[31] Wilson, G. T., \& Davison, G. C. 2014. Behavior therapy and homosexuality: A critical perspective. Behavior Therapy, $5(1), 16-28$.

[32] Wilson, James Q., 1996, “Against Homosexual Marriage," Commentary, 101(3): 34-39. 